\title{
Canada advances Russia's attitude toward AIDS
}

Russia has the fastest growing AIDS epidemic in the world, but it took help from Canadian AIDS experts to advance the issue on the political agenda, says a senior Russian AIDS specialist.

"The attitudes of our health care leaders at the highest levels have been changed," said Dr. Larissa Dementieva of the Russian Ministry of Health.

Dementieva and her colleagues visited Canada in April as part of the Canada AIDS Russia Project. During the 3-year project, funded by a $\$ 2.3$-million grant from the Canadian Internain tional Development Agency, Canadian AIDS experts travelled to Russia to help develop expertise in epidemiology, monitoring, laboratory diagnosis and clinical management of HIV-infected adults and children. Russian HIV $\stackrel{\circ}{\circ}$ specialists have also come to
Canada for internship training. The Russian Ministerial Council on AIDS was created.

"Before, we were treating AIDS from a narrow medical perspective. Now we're establishing wider networks of not just treatment, but support and care," said Dr. Oleg Yurin, a leading clinical specialist on HIV/AIDS.

Although 300000 people are officially registered as HIV-positive in Russia, up from fewer than 10000 cases 5 years ago, only about 2000 Russian receive treatment for HIV/AIDS. Officials estimate the actual number of HIV-positive Russians is closer to 1 million.

Cost is a major obstacle to treatment. In one Russian region, government health insurance programs spend about $\$ 1400$ rubles (Can\$70) per patient annually, Russian officials said. Last year, the federal health ministry spent only Can $\$ 4.4$ million to buy AIDS drugs for the entire country of 145 million people.

The profile of the epidemic is changing in Russia. Two years ago, $85 \%$ of new HIV infections were among injection drug users. That proportion has fallen to about $75 \%$ as HIV has spread to the non-injecting heterosexual population, Dementieva said.

Russia has domestic capacity to produce only AZT and phosphazid, an AZT-like drug; all other drugs must be imported. A grant is pending from the Global Fund to Fight AIDS, Tuberculosis and Malaria to help pay for AIDS treatment, but requires Russia to negotiate with drug companies to bring down the prices of AIDS drugs. - Ann Silversides, Toronto.

\section{Physician SUPply}

\section{Stats Can: $14 \%$ of Canadians have no family doctor}

A comprehensive health survey

$\sim$ released by Statistics Canada in

定 mid June found that more than

one million Canadians have

looked for, but have not been able to find, a family physician.

The Canadian Community Health Survey (CCHS), conducted in 2003, contains the results of responses

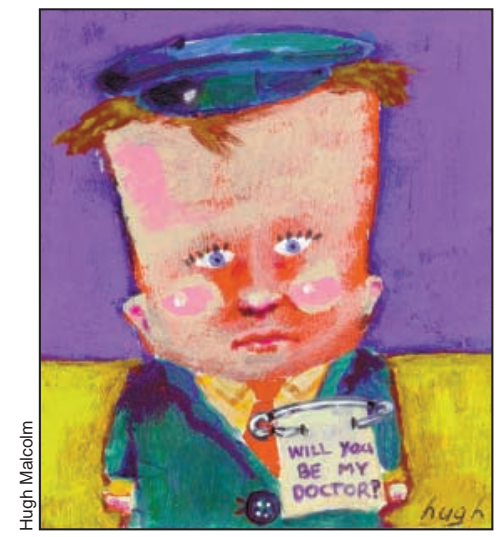
from 135000 Canadians aged 12 and older who were asked more than 1000 questions.

A total of $14 \%$ of Canadians, or 3.6 million people, are without an FP. Of that number, 1.2 million have searched unsuccessfully for an FP. "It's a significant number," said Marc Hamel, a senior analyst at Statistics Canada and the survey's chief. The other 2.4 million
Canadians have not been looking.

More than twice as many men as women indicated that they had not looked for a doctor. Most of those who had not looked were in the 20-34 age group.

"We see there are differences between those who have a doctor and those who don't," said Hamel. "For instance, women are less likely to have a mammogram or Pap smear test if they don't have a regular physician. We also found people were less likely to have their blood pressure checked when they didn't have a regular doctor."

Although it seems to be harder to find an FP in rural areas than urban centres $5.5 \%$ of rural dwellers reported difficulties v. $4.5 \%$ of urbanites), Howard points out that the discrepancy is not as great as most people believe.

"You can easily make the hypothesis that if there is a short- age of physicians, and if people have trouble finding a doctor, that it will be more predominant in rural areas, and the data do not seem to indicate that," Hamel told CMA7.

In $1994,63.1 \%$ of Canadians considered themselves to be in excellent health. That figure fell to $58.4 \%$ in 2003 . Obesity and overweight affect nearly half the population: $14.9 \%$ of adult Canadians considered themselves obese, and $33.3 \%$ said they were overweight. More Canadians are butting out, according to the survey. In 1994 , $29.3 \%$ of the population smoked, and this figure dropped to $22.9 \%$ in 2003 .

One new demographic variable that the survey included was sexual orientation. Nearly twice as many homosexual respondents (21.8\%) had unmet health care needs compared with their heterosexual counterparts (12.7\%). - Louise Gagnon, Ottawa 